\title{
Biomimetics for treatment of endometrial pathologies: an overview
}

\author{
Maria V. Konovalova ${ }^{1}$, Daria S. Tsaregorodtseva ${ }^{1,2}$, Rimma A. Poltavtseva ${ }^{3}$, Elena V. Svirshchevskaya ${ }^{1,3}$ \\ ${ }^{1}$ Shemyakin-Ovchinnikov Institute of Bioorganic Chemistry RAS, Moscow, Russia \\ ${ }^{2}$ Sechenov's First Moscow State Medical University, Moscow, Russia \\ ${ }^{3}$ V. I. Kulakov National Medical Research Center for Obstetrics, Gynecology and Perinatology, Moscow, Russia
}

Elena Svirshchevskaya, PhD, Shemyakin-Ovchinnikov Institute of Bioorganic Chemistry, 16/10 Miklukho-Maklaya St, Moscow, 117997, Russia
Phone: +7 (910) 4648760

Fax: +7 (495) 3304011

E-mail: esvir@mail.ibch.ru

Citation: Konovalova MV, Tsaregorodtseva DS, Poltavtseva RA, Svirshchevskaya EV. Biomimetics for treatment of endometrial pathologies: an overview. Cell Ther Transplant 2020; 9(4): 68-77.

\section{Summary}

Secondary infertility among women in their childbearing age is one of sufficient problems in Russia. It is often caused by damage to the basal layer of endometrium when performing gynecological procedures, e.g., dilatation of uterine cavity, diagnostic curettage, cesarean section, uterine surgey, as well as consequences of complicated pregnancies. As a result, hypo- or hypermetriosis may develop, along with intrauterine adhesions (synechiae), leading to the development of Asherman's syndrome. Despite large amounts of medical data, there are no quite effective ways to treat secondary infertility. Currently, various biological polymers and composite materials based on biopolymers with incorporated active molecules, genetic substances, platelet-rich plasma, stem cells or microvesicles/exosomes of stem cells are used with some success for treatment of hypometriosis and Asherman's syndrome. Gel substances based on sodium hyaluronate, carboxymethylcellulose, polyethylene oxide, collagen and others are certified for clinical use. Biopolymer gels serve, on the one hand, as the materials separating the uterine walls (barrier function), and, on the other hand, they work as carriers of biologically active molecules and cells. Biomimetics can stimulate the regeneration and normalization of endometrium at different efficiency rates, thus promoting restoration of reproductive capacity. Biomimetic-based therapies are under investigation. The present review provides data on treatment efficiency of endometrial disorders by means of biotherapeutic approaches.

\section{Keywords}

Infertility, hypometriosis, Asherman's syndrome, barrier materials, biogels, biomimetics.

\section{Introduction}

Depopulation of the indigenous community is among the most urgent problems for Russia with its vast territories. Current total birth rate (TBR) in Russia is $1.3-1.5$, which is lower than required for simple reproduction of the population (should be $\approx 2.12$ [1]). It is obvious that the decline in TBR is observed in all industrial countries, where the majority of the population is concentrated in the cities. The depopulation process cannot be stopped completely, but it can be slowed down by socio-economic changes, as well as by reducing secondary infertility of women in their childbearing age.
Primary infertility is the inability to give birth to the first child. This index decreases by $0.1 \%$ per year, being about $1.9 \%$ [2]. Secondary infertility is the inability to give birth to children after a successful first pregnancy. The prevalence of secondary infertility increases sharply with age - from $2.6 \%$ in women aged $20-24$ years to $27.1 \%$ in women aged $40-44$ years [2]. At the same time, in Russia and other Central and Eastern Europe countries, as well as in Central Asia, secondary infertility is detected in $18 \%$ of women aged $20-44$ years, compared to only $7.2 \%$ in the high-resource countries [2,3]. Different disorders of uterine endometrium resulting from disturbed pregnancies or various interventions are the main cause of secondary infertility. 


\section{Prevention of endometrial disorders}

The endometrium is a complex, multicomponent system consisting of the integumentary and glandular epithelium, stroma, basic substance, and blood vessels. The epithelial component of the endometrium consists mainly of secretory and ciliated cells, as well as a few reticular cells, fibroblasts, macrophages, lymphocytes and labrocytes. The human endometrium is a dynamic tissue that undergoes periods of growth and death during the menstrual cycle. Endometrial growth is regulated by the balance between estrogen and progesterone [4]. If this balance is disturbed, hyperplasia (with a deficiency of progesterone) or hypoplasia (with a deficiency of estrogen) of the endometrium may occur.

Both hyperplasia and hypoplasia are causes of infertility. In hyperplasia, there is an overgrowth of the endometrium and uterine stroma, including the release of endometrial cells into the muscle layer and abdominal cavity. With hypoplasia, decreased thickness of the internal uterine mucosa is noted. Thickness of the endometrial layer should range between 7 and $13 \mathrm{~mm}$ for successful fertilization. Under the borderline conditions, the attachment of an egg to the endometrium is possible, but miscarriages are more common. Endometrial hyperplasia was found in $70-80 \%$ of cases when examining women with infertility. Changes in endometrial thickness may be often caused by metabolic and neuroendocrine disorders. To arrange appropriate management, the major reasons for endometrial disorders should be identified.

Adhesive plaques (synechiae) form in the uterus following surgical interventions (abortions, curettage, complicated pregnancies), the condition known as Asherman's syndrome (AS) [5]. Synechiae are outgrowths (adhesions) of the sclerotized endometrium that disturb normal anatomy and physiology of the uterine mucosa [6]. The main cause of AS is damage and trauma to the basal layer during gynecological procedures. Less often, intrauterine synechiae are formed after endometritis, the uterine mucosa inflammation caused by schistosomiasis or genital tuberculosis [7]. Synechiae are also formed in intrauterine adhesion (IUA), a disease of the uterus with aberrant occurrence of adhesions within uterus and/or cervix. Patients with IUA often have menstrual irregularities and suffer from pelvic pain. IUA can prevent blastocyst implantation, impair blood supply to the uterus and early fetus, and finally lead to miscarriage or complete infertility in patients.

The leading factor in the formation of synechiae is considered to be mechanical trauma of basal endometrial layer after childbirth or abortion (wound phase). Pathomorphology of intrauterine synechiae is still unclear. A major role in pathogenesis of intrauterine adhesions is assigned to macrophages, the cellular mediators of inflammation. After mechanical damage, macrophages show increased phagocytic and secretory activity and, within 5 days, become the main component of local leukocyte population. Macrophages promote the migration of new mesothelial cells to the damaged surface, which initially form small "islands" on the damaged surface, and then thin layers of mesothelial cells [8].
Certain cytokines, such as fibroblast growth factor (bFGF), platelet growth factor (PDGF), and transforming growth factor $\beta 1$ (TGF- $\beta 1$ ) seem to be involved in the pathogenesis [9]. The role of chemokines and chemokine receptors CXL12/CXCR4/CXCR7 axis in the development of AS was also shown: interaction of the CXCL12 chemokine with the CXCR4 receptor in mouse models caused a decrease in fibrosis and improved fertility [10]. Wang et al. studied the role of nuclear factor-kappaB (NF-KB) in the AS pathogenesis. As a result, NF-KB expression was significantly increased in endometrial samples from the AS patients compared to the control group. The role of NF-KB in the pathogenesis of AS was further confirmed in a rat model [11]. Xue et al. found that expression of TGF- $\beta$ and connective tissue growth factor (CTGF) in endometrial tissue with adhesions was significantly increased. Moreover, the activity of the NF$\mathrm{KB}$ signaling pathway in endometrial tissue with synechiae was also higher and positively correlated with expression of TGF- $\beta$ and CTGF. Blocking the NF-KB signaling pathway with a specific inhibitor led to a decrease in TGF- $\beta$ expression in RL95-2 cells, which confirmed an association between NF-KB and TGF- $\beta$ signaling pathway in endometrial cells. In addition, the expression of TGF- $\beta$ and CTGF has been associated with the recurrent IUA, so it can be used as a potential marker of IUA pathology [12].

Chronic activation of cellular and humoral proinflammatory responses is accompanied by increased production of cytokines and other biologically active substances that cause microcirculation disorders, exudation and deposition of fibrin in the endometrial layer, which forms connective tissue fibrinous adhesions in the stroma and/or intrauterine synechia of varying severity. In numerous studies, biopsies obtained from patients with intrauterine adhesions compared to patients with normal endometrium contained $50-80 \%$ of fibrous tissue versus $13-20 \%$, respectively. Due to the fact, that placental tissue fragments can cause fibroblast activation and collagen formation before endometrial regeneration. Occurrence of intrauterine synechiae is more likely in patients with missed abortion than in patients with incomplete abortion. In terms of possible injury to the uterine mucosa, the first 4 weeks after delivery or termination of pregnancy are considered most dangerous. From the histological point of view, endometrial stroma in AS is replaced by fibrous tissue, and the uterine glands are replaced by inactive cubic epithelium that is insensitive to hormonal stimulation. As a result, the normal anatomy and physiology of the uterine mucosa change.

When synechiae are formed, endometrial cells can grow in the muscle layer, which leads to endometriosis. Due to a difficult vaginal discharge of menstrual blood, the endometrium enters abdominal cavity via fallopian tubes. Menstrual blood contains stem cells that may grow in such inappropriate microenvironment.

Hormone therapy is ineffective in AS. The main method of treatment is surgical removal of synechiae, which is problematic in severe cases, due to the inability to locate the adhesions (fusions of the uterine walls). Despite the removal of adhesions, they are re-formed in $25 \%$ of women with moderate AS and 75\% with severe pathology. Pregnancy occured 
in $25-75 \%$ of operated women, full-term children were born in $26-79 \%$ of cases. Different results are reported, due to absence of generally recognized AS classification and lack of common approach to secondary prevention of the disease [13].

\section{Endometrium regeneration using surface-functionalized hydrogels}

Recovery of the uterine endometrium is facilitated by introduction of various biological substances that are able to stimulate regeneration of the tissue leading to restoration of reproductive capacity [14]. Type of biomaterial is an important factor in tissue engineering since it may provide structural support mimicking native uterine endometrial tissues [15]. The biomimetic should include a supporting layer and biologically active molecules. Both components should facilitate cellular and extracellular signaling, nutrient transport, stem cell recruitment, proliferation, and differentiation. The biomaterials can release drugs, growth factors, small molecules, and other biologically active compounds in a controlled manner. Recent studies have shown that, in addition to traditional regeneration of uterus promoted by the biomaterials, their combination with modified cells, e.g., cell layers, intercellular boundaries, surface-functionalized frameworks and decellularized biological tissue, may also exhibit functional or structural advantages. These approaches may provide recovery of altered uterine structures to some degree by inducing biomimetic changes and restoring the regenerative microenvironment [16, 17].

\section{Regeneration of endometrium with modified hydrogels}

Many endometrial regeneration strategies are focused on modifying the surface or structure of gels for better biocompatibility and stronger adhesion to endometrial surface; delivery of bioactive growth factors, hormones, and extracellular vesicles [18, 19]. Li et al. [19] developed a collagen hydrogel loaded with fibroblast growth factor bFGF conjugated to the collagen-binding domain (CBD). This combination significantly reduced the random bFGF diffusion in vivo and increased the delivery of the factor to the endometrium. Recombinant proteins with CBD were released in the damaged area and maintained an effective concentration for a long time. The complex framework induced high neovascularization, alignment of muscle fibers and thick layers of the endometrium which contributed to effective tissue recovery. However, the incidence of pregnancy in this study was low, indicating that functional recovery of the endometrium was not achieved. Similarly, Lin et al. [20] loaded vascular endothelial growth factor VEGF conjugated with CBD onto a collagen scaffold to improve angiogenesis and endometrial re-epithelization. The authors compared the efficacy of free growth factor, and VEGF included in the gel, aiming for regeneration of a full-layer injury in rat uterus. The resulting growth of vascular tissue provided the damaged areas with nutrients and oxygen. In addition, targeted VEGF release activated matrix metalloproteinases and initiated endometrial remodeling by increasing the number of inflammatory cells at early regeneration stages. The results showed a $31.2 \%$ improvement in pregnancy rate when using CBD/VEGF collagen gel (50.0\%) compared to only local VEGF injection (18.8\%).

Xu et al. [21] used a temperature-sensitive hydrogel loaded with keratinocyte growth factor KGF, which stimulates tissue repair. The hydrogel made it possible to control release and long-term retention of the drug in damaged uterus. The authors found that the modified KGF-hydrogel framework promoted cell autophagy by inhibiting the mammalian rapamycin signaling pathway; improved the expression level of the CD31 stem cell marker; endothelial migration and proliferation of endometrial glandular epithelial cells and luminal epithelial cells. Functional repair of the epithelium was due to the restoration of corresponding microenvironment by reducing inflammation and immune responses $[22,23]$.

In addition to biologically active proteins some studies aimed at restoring the endometrium have analyzed a role of secreted extracellular vesicles derived from stem cells [17, 22, 24]. A modified stem cell secretome-containing hydrogel was based on hyaluronic acid (HA), which increased the release of a number of regeneration-related growth factors, such as epidermal growth factor EGF, bFGF, insulin-like growth factor IGF-1, and IGF-binding protein IGFBP. The cross-linked gel served as a carrier and increased in vivo retention time for the stem cell secretions, thus been associated with an increase in endometrial thickness and higher number of endometrial glands if compared to the usage of non-modified gel. Nanoscale functionalization of endometrial scaffolds simulates the natural environment, provides stable release of bioactive molecules and transmission of signals from extracellular vesicles during uterine regeneration [25].

\section{Endometrium regeneration on the basis of of gel-cell scaffolds}

\section{Endometrial mesenchymal cells}

Biomaterials provide structural and mechanical support to help restoration of the architecture and functionality of damaged tissues. However, the scaffold biomaterial is not sufficient enough to repair large uterine defects. Vascularization, recruitment of native cells, and inhibition of scar formation should be considered [26]. Cell culture on the scaffold structures increases biological functions, prolonging cell survival and stimulating cell proliferation, differentiation, and vascularization [27]. E.g., the resident mesenchymal stromal cells (MSCs) could be incorporated into the polymer gels. Kim et al. [28] used endometrial mesenchymal stromal cells (dEMSCs) encapsulated in a HA hydrogel in a mouse model of uterine infertility. Two weeks after the injury, the fibrous tissue decreased and the endometrial thickness increased. The authors showed increased expression of embryonic markers, including desmin, CD44, and platelet endothelial cell adhesion molecules in regenerating endometrium. Successful implantation of the transferred embryos was accompanied by normal development and live birth of offspring after treatment of the damaged uterus with the dEMSC-HA hydrogel. Isotopic analysis of endometrial cell proliferation showed a significant reduction in recovery time with 
dEMSC-HA compared to isolated mesenchymal stem cells from bone marrow or endometrium. The gels were gradually eliminated from the uterus, due to HA-degrading hyaluronidase activity in uterus, thus allowing the incorporated cells to attach to endometrium in the damaged area and temporarily provide rigidity of the framework necessary for endometrial regeneration.

dEMSCs exert protective effect not only in patients with hypometriosis, but also at the AS. For example, a group of 7 patients suffering from severe AS underwent triple irrigation of uterine cavity with a suspension of autologous menstrual blood-derived endometrial stem cells. In all women, this treatment, along with additional estrogen therapy, was followed by increased endometrium thickness. In 5 out of 7 patients, the thickness reached $7 \mathrm{~mm}$ or more, thus being sufficient for implantation. Moreover, one of these women soon became pregnant in natural way, and two more, due to extracorporeal fertilization [29].

\section{Endometrial perivascular cells}

These cells could be also applied to promote local vascularization. Their ability to restore angiogenesis and inhibit scar formation when choosing cell types for uterine repair is of fundamental importance. Endometrial perivascular cells (En-PSCs) carrying CD146 markers and platelet growth factor receptor PDGFR- $\beta$ loaded into a collagen gel had a similar effect upon stem cells in the endometrial layer [30]. En-PSCs, if additionally transfected with the CYR61 angiogenic inducer, were shown to promote vascular formation. Development of CYR61-transfected En-PSC-loaded collagen scaffold significantly increased the density of blood vessels, since it stimulated release of angiogenic factors from extracellular matrix and, generally, accelerated the in vivo neovascularization.

\section{Bone marrow-derived mesenchymal stromal stem cells}

A significant number of studies show the effectiveness of stem cells derived from bone marrow (BMSCs) for endometrial and uterine regeneration due to their ease of isolation and reparative potential [31-33]. Administration of BMSCs, supplemented by cauterization (electroacopuncture), improved fertility by activating the CXCR4 chemokine receptor, enhanced expression of cytokeratins and vimentin, VEGF and bFGF [31]. Effect of BMSCs incorporated into polyglycerol sebacinate (PGS) gel was compared with effect of BMSC-loaded collagen, or polylactic and glycolic acid (PLGA) copolymer gels. The authors showed an increase in TGF- $\beta 1$, bFGF synthesis, and better recovery of endometrial morphology when using PGS gel. However, the fertility rates were comparable to those achieved with collagen-based gel (72\%), but higher than with PLGA carrier (42\%) [34]. Similar data were reported by Qi et al. [32]. The authors studied ability of BMSCs-PGS scaffolds for restoration of uterine soft tissue deformities under various dynamic conditions without external stimuli. The authors compared efficacy of the materials loaded with different cell types. PGS with BMSCs showed better stimulation of endometrial proliferation and differentiation. Moreover, the in vivo studies have shown longer retention time for BMSCs in situ and more effective vascularization of the PGS scaffold.
Yang et al. [33] used BMSCs encapsulated in a gel based on pluronic F-127 (PF-127) and vitamin C, which resulted in an increased membrane stability. In addition, vitamin $\mathrm{C}$ reduced the secretion of TNF- $\alpha$ and interleukin 6 (IL-6) due to its antioxidant activity, maintained redox homeostasis, and promoted a pro-regenerative trend by increasing the IL-10 levels. BMSC/PF-127+vitamin C hydrogel restored endometrial thickness and reduced fibrous areas of endometrial stromal tissues.

Meanwhile, the BMSCs therapy in patients with AS still lacked efficiency in terms of fertility. Indeed, introduction of autologous BMSCs into subendometrial myometrium in 6 women suffering from AS stimulated an increase in endometrial thickness and normalized menstrual cycles, but this biological effect in all patients did not result into successful extracorporeal fertilization attempts [35].

\section{Umbilical cord mesenchymal stromal cells}

Wharton's jelly of the umbilical cord is an alternative source of MSCs, from which stem cells are isolated (UCMSCs). Introduction of UCMSCs as a component of a collagen carrier improved endometrial proliferation, differentiation, and neovascularization after implantation of UCMSCs scaffolds into the endometrium [36]. All 26 patients with AS showed positive dynamics, increased endometrial thickness, and decreased the number of intrauterine adhesions. Ten patients soon became pregnant after completing the treatment. The newborn children were born without any obvious birth defects or placental pathology. UCMSCs mixed with gelatin and collagen fibers stimulated pronounced angiogenesis and reduced scar formation in the damaged area. The composite cell framework destroyed collagen in the scarred areas, probably, by increasing the amount of matrix metalloproteinase 9, FGF-2, and VEGF, and led to angiogenesis and cyclic endometrial regeneration [37]. Xin et al. [38] found that the UCMSC-loaded collagen scaffold reduced cell apoptosis and improved the state of endometrial stromal cells due to eventual paracrine action. The scaffold did not induce inflammation and contributed to collagen remodeling in regenerating endometrium. In addition, the UCMSCs-loaded collagen scaffold induced early rapid re-epithelization by increasing level of cell proliferation and expression of cytokeratin, which is vital for the subsequent endometrial repair after damage.

\section{Growth effects of platelet-rich plasma}

Inclusion of platelet-rich plasma (PRP) in the structure of hydrogels is a point for research of uterine endometrial regeneration. In a number of studies, PRP was used to stimulate MSCs obtained from the menstrual blood. Transplantation of these MSCs stimulated thickening of the endometrium [39].

In women who underwent endometrial electroacupuncture for the first time, the effect of autologous PRP administration on endometrial thickness was evaluated. PRP infusion resulted in endometrial thickening up to $7 \mathrm{~mm}$ observed 48 72 hours later. Successful pregnancy occurred then after progesterone administration [40]. Similar data were obtained in a randomized clinical trial $(n=83)$ among women with hypometriosis suffering from poor endometrial response 
to standard hormone replacement therapy. After PRP administration, there was a significant increase in endometrial thickness; in this group, the frequency of implantation and clinical pregnancy per cycle also increased significantly [41].

Application of autologous PRP in rat model with ethanol-induced endometrial injury led to endometrial regeneration. The authors concluded that intrauterine administration of autologous PRP stimulates and accelerates endometrial regeneration, along with reduced formation of fibrosis [42].

There are also studies in which the authors did not show that intrauterine PRP injection improves the results of hysteroscopy after surgical removal of intrauterine adhesions [43].

\section{Hypothetical mechanisms of stem cell actions}

Most research groups did not show real engraftment of transplanted mesenchymal cells, which confirms the current opinion about paracrine nature of therapeutic effects caused by allogeneic MSCs [44-48].

Cellular elements can be administered to patients as intravascular infusions $[49,50]$, intramuscularly [51] or directly into the uterine cavity. Both enriched MSCs or stromal cell suspensions can be used $[35,52,53]$. No serious side effects or signs of cell engraftment were observed in these studies. There is no doubt that further research and clinical trials are needed to optimize the use of cell therapy.

In healthy female body, cytokine environment and immune cellular repertoire depend on the phase of menstrual cycle [44], which are important for reducing fibrosis and restoration of endometrium. It is believed that successful endometrial repair technology is directly related to the activity of local inflammation. To achieve maximal therapeutic effect, it is necessary to ensure optimal mechanism and timely delivery of cellular elements, depending on the cycle phase. It is also necessary to minimize potential risks associated with the delivery method. For example, AS is often associated with disturbed blood flow in uterine spiral arterioles. Therefore, intravascular administration of these cellular elements cannot be used in this case.

Currently, most researchers believe that stem cells can only have a systemic and paracrine therapeutic effect, since they, probably, act as immunomodulators $[46,54,55]$. Immunomodulatory effects result from destruction of these cells or their absorption. This may explain the reparative tissue response during local injection of MSCs [56].

It is also suggested that the release of paracrine factors may represent the main effect of cellular therapy. In this case, the usage of exosomes/microvesicles opens some prospectives for regenerative medicine [57]. E.g., excretory microvesicles (eMVs) isolated from intrauterine fluid also have a protective effect [57-60]. In addition, MSCs have been shown to produce eMVs that have immunomodulatory effect on $\mathrm{T}$ cells [61].

During experiments on co-cultivation of mouse embryos and endometrial sMVs, an increase in the number of blastomeres, as well as vascular epithelium and platelets in embryos was observed [62]. These results led to the attempts of intrauterine infusion of PRP which includes eMVs components. In clinical trials, PRP infusion increased epithelial thickness $[40,63,64]$, and, as a result, the number of successful implantations and natural pregnancies occurred. The fact that exosomes and other eMVs are an alternative to "direct" cell therapy and allow avoiding its negative consequences is confirmed by the high efficiency of PDGF- $\alpha$, which is contained in platelets, in tissue repair and regeneration [65].

\section{Clinical usage of antiadhesive polymers to prevent Ascherman's syndrome}

As noted above, the AS adhesions within uterus make it difficult to outflow menstrual blood and reduce women's fertility. Hormone therapy is not effective for AS. The main method of therapy is the removal of adhesions in one way or another. After removing the adhesions, new endometrial damage occurs, which often leads to the formation of the adhesions de novo. To prevent the formation of new adhesions, a number of studies have suggested using copolymers of hyaluronic acid and carboxymethylcellulose etc. for temporary separation of the uterine walls, which can provide the time required for re-epithelization of the wound surface.

For the prevention of AS and IUA in Russia and worldwide, various anti-adhesive materials are used, for example, Antiadhesin (Russia), Seprafilm film (France) based on sodium hyaluronate and sodium salt of carboxymethylcellulose (HA-CMC), Oxiplex/AP gel (USA) based on carboxymethylcellulose (CMC) and polyethylene oxide [8, 66-68], and others.

The use of barrier anti-adhesive agents based on HA-CMC reduces the risk of adhesion formation in the uterine cavity. According to a randomized study [68], intrauterine administration of an anti-adhesive barrier agent containing HA and CMC can not only prevent the formation or reduce the severity of intrauterine adhesions, but also contributes to the preservation of reproductive function. A total of 150 patients with incomplete or missed abortions participated in the clinical study. In the treatment group (Seprafilm) $(n=50)$, membranes were inserted into the endometrial and cervical canal cavity after suction evacuation and/or curettage. The control group $(n=100)$ did not get any treatment. Both groups were divided into two subgroups: patients who had no previous suction or curettage, and those who had at least one previous abortion or curettage. Further fertility was assessed by pregnancy success in all groups. The formation of endometrial synechiae was evaluated using hysterosalpingography in patients of all groups without pregnancy success 8 months after the intervention. The safety of using Seprafilm was evaluated by recording any adverse reactions and performing ultrasound monitoring. Of the subgroups without previous abortions, all 32 patients (100\%) who received Seprafilm became pregnant in the next 8 months; in the control group, pregnancy occurred only in $54 \%$ of cases. They also showed that patients in the Seprafilm group with one or more previous interventions and no pregnancy after 8 months did not have adhesions in $90 \%$ of cases, and only in $50 \%$ of cases in the untreated group.

HA performs important physiological functions in the body, including joint lubrication, regulation of blood vessel wall 
permeability, regulation of protein and electrolyte transport, and wound healing. HA can bind to a large number of water molecules improving tissue hydration, increasing cell resistance to mechanical damage, and reducing post-traumatic formation of granulation and fibrous tissue. Due to its unique biocompatibility and enzymatic biodegradation, HA is often used to prevent postoperative adhesions $[69,70]$. HA gel significantly reduces the frequency of IUA after intrauterine surgery, regardless of the type of intervention or the presence of primary diseases. It has been shown that treatment with HA gel increases the frequency of pregnancy after intrauterine surgery [71].

\section{Heat-sensitive matrices based on poly-N-isopropylacrylamide}

Poly-N-isopropylacrylamide (PNIPAM) is a polymer that performs a phase transition from a liquid to a gel state when heated above $37^{\circ} \mathrm{C}$. As the temperature rises, PNIPAM forms a three-dimensional hydrogel that compresses and pushes the liquid out, releasing the contents into the surrounding tissue. Accordingly, PNIPAM, when administered, provides separation of the uterine walls. At the same time, it creates an enriched environment around itself that stimulates endometrial regeneration. Unlike PNIPAM, HA and CMC swell in the uterus, collecting intrauterine fluid and filling the internal volume. Theoretically, PNIPAM may be more promising for preventing adhesions. Currently, PNIPAM gels are being studied in vitro and in model systems, for example, for the cultivation of chondrocytes. Incubation of chondrocytes with PNIPAM showed that the cells were viable for 24 days, increased in number, and produced type II collagen and glycosaminoglycans [72].

For the functionalization of hydrogels, modification of PNIPAM is possible by including hydrophilic bioactive substances, such as cell culture supernates, eMVs or exosomes of MSCs, PRP, and other molecules. This modification may separate thermosetting and hydrophilic functions and allows each component to act independently. This concept was demonstrated by the Yoshioka group, who developed a tissue culture framework based on PNIPAM-graft-PEG [73-75]. The authors modified PNIPAM by including butyl ether of methacrylic acid in order to shift the phase transition point to a lower temperature. In subsequent studies in cell culture, the authors reported a system with a gelation temperature of $7^{\circ} \mathrm{C}$ in the cell culture medium [76]. It is known that thermosetting polymers with a hydrophobic component form dispersed gels in aqueous media above the critical point when the concentration exceeds the critical minimum. This phenomenon is associated with particle aggregation due to thermosetting flocculation of Poly(styrene-graft-NIPAM) particles [77, 78]. Poly(styrene-co-NIPAM) particles were used to form core-shell solid particles. Recently, thermosetting dispersed gels with Poly- $\varepsilon$-caprolactone cores and shells consisting of a polyethylene glycol brush were also obtained. Microdispersion procedure allowed to produce gels which were used as a thermally reversible cell culture system for mouse 3T3 fibroblasts [79] or C2C12 myoblasts [80].

\section{Conclusions}

The use of biopolymers and biomimetics based on combinations of polymers with various growth factors or live cells opens up new opportunities for the treatment of endometrial disorders. To this purpose, practical clinicians use gels based on hyaluronic acid, carboxymethyl cellulose, collagen, polyethylene oxide and others with certain efficiency. The main task of biopolymers is to separate the walls of the uterus, thus preventing synechiae, e.g., in Asherman's syndrome. To improve treatment of hypo- and hypermetriosis, the gels should contain appropriate biological factors able to stimulate or inhibit the endometrial growth. Most of such biomimetic substances are currently at the pre-clinical testing stage. Some data from clinical studies have shown promising results of this approach for the treatment of female infertility.

\section{Conflict of interest}

Authors declare no conflict of interest.

\section{Acknowledgements}

The work was supported by the Ministry of Health of the Russian Federation for 2020-2022 (no. AAAA-A20-120022790039-1).

\section{References}

1. Borisov VA, Demography, Publishing House NOTABENE; 2001. 272 p. (In Russian).

2. Mascarenhas MN, Flaxman SR, Boerma T, Vanderpoel S, Stevens GA. National, Regional, and Global Trends in Infertility Prevalence Since 1990: A Systematic Analysis of 277 Health Surveys. Low N, ed. PLoS Med. 2012;9(12):e1001356. doi:10.1371/journal.pmed.1001356.

3. Infertile Marriage. Modern approaches to Diagnosis and Treatment. Textbook (Ed.: GT Sukhykh). Moscow: GEOTAR-Media; 2010 (In Russian).

4. Mahajan N, Sharma S. The endometrium in assisted reproductive technology: How thin is thin? J Hum Reprod Sci. 2016;9(1):3-8.

5. Zhu HY, Ge TX, Pan Y Bin, Zhang SY. Advanced Role of Hippo Signaling in Endometrial Fibrosis: Implications for Intrauterine Adhesion. Chin Med J. 2017;130(22):27322737.

6. Dreisler E, Kjer JJ. Asherman's syndrome: Current perspectives on diagnosis and management. Int J Womens Health. 2019;11:191-198.

7. Engelbrechtsen L, Istre O. Asherman syndrome. In: Minimally Invasive Gynecological Surgery. Springer Berlin Heidelberg; 2015:43-48.

8. Arutyunova EE, Buralkina NA, Chuprynin VD, Zhorova VE. Pathogenetic justification and experience in using anti-adhesion gel in patients with intrauterine synechia after surgical hysteroscopy. Medical Council. 2018;(13):160-164. (In Russian)

9. Tao Z, Duan H. Expression of adhesion-related cytokines in the uterine fluid after transcervical resection of adhesion. Zhonghua Fu Chan Ke Za Zhi. 2012;47(10):734-737. (In Chinese). 
10. Krikun G. The CXL12/CXCR4/CXCR7 axis in female reproductive tract disease: Review. Am J Reprod Immunol. 2018;80(5).

11. Wang X, Ma N, Sun Q, Huang C, Liu Y, Luo X. Elevated NF- $\kappa \mathrm{B}$ signaling in Asherman syndrome patients and animal models. Oncotarget. 2017;8(9):15399-15406.

12. Xue X, Chen Q, Zhao G, Zhao JY, Duan Z, Zheng PS. The overexpression of TGF- $\beta$ and CCN2 in intrauterine adhesions involves the NF-KB signaling pathway. PLoS One. 2015;10(12)

13. Makarenko TA, Nikiforova DE. Modern opportunities in the treatment of Asherman syndrome. Mother and child. 2016;(15):1001-1004 (In Russian).

14. Cervelló I, Santamaría X, Miyazaki K, Maruyama T, Simón C. Cell Therapy and Tissue Engineering from and toward the Uterus. Semin Reprod Med. 2015;33(05):366-372.

15. Zhang SS, Xu XX, Xiang WW, Zhang HH, Lin HL, Shen LE, et al.. Using $17 \beta$ estradiol heparin poloxamer thermosensitive hydrogel to enhance the endometrial regeneration and functional recovery of intrauterine adhesions in a rat model. FASEB J. 2020;34(1):446-457.

16. Liu F, Hu S, Wang S, Cheng K. Cell and biomaterial-based approaches to uterus regeneration. Regen Biomater. 2019;6(3):141-148.

17. Liu F, Hu S, Yang H, Li Z, Huang K, Su T, et al. Hyaluronic Acid Hydrogel Integrated with Mesenchymal Stem Cell-Secretome to Treat Endometrial Injury in a Rat Model of Asherman's Syndrome. Adv Healthc Mater. 2019;8(14):e1900411.

18. Shadish JA, Benuska GM, DeForest CA. Bioactive site-specifically modified proteins for 4D patterning of gel biomaterials. Nat Mater. 2019;18(9):1005-1014.

19. Li C, Ouyang L, Pence IJ, Moore AC, Lin Y, Winter CW, Armstrong JPK, Stevens MM. Buoyancy-Driven Gradients for Biomaterial Fabrication and Tissue Engineering. Adv Mater. 2019;31(17):e1900291.

20. Lin N, Li X, Song T, Wang J, Meng K, Yang J, et al. The effect of collagen-binding vascular endothelial growth factor on the remodeling of scarred rat uterus following full-thickness injury. Biomaterials. 2012;33(6):1801-1807.

21. Xu HL, Xu J, Zhang SS, Zhu QY, Jin BH, ZhuGe DL, et al.Temperature-sensitive heparin-modified poloxamer hydrogel with affinity to KGF facilitate the morphologic and functional recovery of the injured rat uterus. Drug Deliv. 2017;24(1):867-881.

22. Zhang Y, Lin X, Dai Y, Hu X, Zhu H, Jiang Y, Zhang S. Endometrial stem cells repair injured endometrium and induce angiogenesis via AKT and ERK pathways. Reproduction. 2016;152(5):389-402.

23. Gargett CE, Chan RWS, Schwab KE. Hormone and growth factor signaling in endometrial renewal: Role of stem/progenitor cells. Mol Cell Endocrinol. 2008;288(12):22-29.
24. Azizi R, Aghebati-Maleki L, Nouri M, Marofi F, Negargar S, Yousefi M. Stem cell therapy in Asherman syndrome and thin endometrium: Stem cell- based therapy. Biomed Pharmacother. 2018;102:333-343.

25. Han Q, Du Y. Advances in the Application of Biomimetic Endometrium Interfaces for Uterine Bioengineering in Female Infertility. Front Bioeng Biotechnol. 2020;8:153.

26. Owusu-Akyaw A, Krishnamoorthy K, Goldsmith LT, Morelli SS. The role of mesenchymal-epithelial transition in endometrial function. Hum Reprod Update. 2019;25(1):114133.

27. Frost BA, Sutliff BP, Thayer P, Bortner MJ, Foster EJ. Gradient poly(ethylene glycol) diacrylate and cellulose nanocrystals tissue engineering composite scaffolds via extrusion bioprinting. Front Bioeng Biotechnol. 2019;7:280.

28. Kim S, Kim M, Jung S, Kwon K, Park J, Kim S, et al. Co-delivery of therapeutic protein and catalase-mimic nanoparticle using a biocompatible nanocarrier for enhanced therapeutic effect. J Control Release. 2019;309:181-189.

29. Reynolds K, Khoury J, Sosnowski J, Thie J, Hofmann G. Comparison of the effect of tamoxifen on endometrial thickness in women with thin endometrium $(<7 \mathrm{~mm})$ undergoing ovulation induction with clomiphene citrate. Fertil Steril. 2010;93(6):2091-2093.

30. Li Z, Yan G, Diao Q, Yu F, Li X, Sheng X, et al. Transplantation of human endometrial perivascular cells with elevated CYR61 expression induces angiogenesis and promotes repair of a full-thickness uterine injury in rat. Stem Cell Res Ther. 2019;10(1):179.

31. Xia L, Meng Q, Xi J, Han Q, Cheng J, Shen J, et al. The synergistic effect of electroacupuncture and bone mesenchymal stem cell transplantation on repairing thin endometrial injury in rats. Stem Cell Res Ther. 2019;10(1):244.

32. Qi Y, Lohman J, Bratlie KM, Peroutka-Bigus N, Bellaire $\mathrm{B}$, Wannemuehler $\mathrm{M}$, et al. Vitamin $\mathrm{C}$ and B 3 as new biomaterials to alter intestinal stem cells. J Biomed Mater Res Part A. 2019;107(9):1886-1897.

33. Yang H, Wu S, Feng R, Huang J, Liu L, Liu F, Chen Y. Vitamin $\mathrm{C}$ plus hydrogel facilitates bone marrow stromal cell-mediated endometrium regeneration in rats. Stem Cell Res Ther. 2017;8(1):267.

34. Xiao B, Yang W, Lei D, Huang J, Yin Y, Zhu Y, et al. PGS Scaffolds Promote the In Vivo Survival and Directional Differentiation of Bone Marrow Mesenchymal Stem Cells Restoring the Morphology and Function of Wounded Rat Uterus. Adv Healthc Mater. 2019;8(5):1801455.

35. Panchal S, Patel H, Nagori C. Endometrial regeneration using autologous adult stem cells followed by conception by in vitro fertilization in a patient of severe Asherman's syndrome. J Hum Reprod Sci. 2011;4(1):43.

36. Cao Y, Sun H, Zhu H, Zhu X, Tang X, Yan G, et al. Allogeneic cell therapy using umbilical cord MSCs on collagen scaffolds for patients with recurrent uterine adhesion: a phase I clinical trial. Stem Cell Res Ther. 2018;9(1):192. 
37. Xu L, Ding L, Wang L, Cao Y, Zhu H, Lu J, et al. Umbilical cord-derived mesenchymal stem cells on scaffolds facilitate collagen degradation via upregulation of MMP-9 in rat uterine scars. Stem Cell Res Ther. 2017;8(1):1-13.

38. Xin L, Lin X, Pan Y, Zheng X, Shi L, Zhang Y, et al. A collagen scaffold loaded with human umbilical cord-derived mesenchymal stem cells facilitates endometrial regeneration and restores fertility. Acta Biomater. 2019;92:160-171.

39. Zhang S, Tan J, Li P. Co-transplantation of menstrual stromal cell and platelet-rich plasma improves Asherman's syndrome in rat model. Fertil Steril. 2017;108(3):e193.

40. Chang Y, Li J, Chen Y, Wei L, Yang X, Shi Y, Liang X. Autologous platelet-rich plasma promotes endometrial growth and improves pregnancy outcome during in vitro fertilization. Int J Clin Exp Med. 2015;8(1):1286-1290.

41. Eftekhar M, Neghab N, Naghshineh E, Khani P. Can autologous platelet rich plasma expand endometrial thickness and improve pregnancy rate during frozen-thawed embryo transfer cycle? A randomized clinical trial. Taiwan J Obstet Gynecol. 2018;57(6):810-813.

42. Jang HY, Myoung SM, Choe JM, Kim T, Cheon YP, Kim YM, Park H. Effects of Autologous Platelet-Rich Plasma on Regeneration of Damaged Endometrium in Female Rats. Yonsei Med J. 2017;58(6):1195.

43. Javaheri A, Kianfar K, Pourmasumi S, Eftekhar M. Platelet-rich plasma in the management of Asherman's syndrome; An RCT. Int J Reprod Biomed. 2020;18(2):113-120.

44. von Bahr L, Batsis I, Moll G, Hägg M, Szakos A, Sundberg B, et al. Analysis of Tissues Following Mesenchymal Stromal Cell Therapy in Humans Indicates Limited LongTerm Engraftment and No Ectopic Tissue Formation. Stem Cells. 2012;30(7):1575-1578.

45. Golle L, Gerth HU, Beul K, Heitplatz B, Barth P, Fobker $\mathrm{M}$, et al. Bone marrow-derived cells and their conditioned medium induce microvascular repair in uremic rats by stimulation of endogenous repair mechanisms. Sci Rep. 2017;7(1):9444.

46. Lupatov AY, Poltavtseva RA, Bystrykh OA, Yarygin KN, Sukhikh GT. Neural stem/progenitor cells maintained in vitro under different culture conditions alter differentiation capacity of monocytes to generate dendritic cells. J Stem Cells Regen Med. 2017;13(2):54-61.

47. Li B, Zhang Q, Sun J, Lai D. Human amniotic epithelial cells improve fertility in an intrauterine adhesion mouse model. Stem Cell Res Ther. 2019;10(1):257.

48. Poltavtseva RA, Poltavtsev A V., Lutsenko G V., Svirshchevskaya E V. Myths, reality and future of mesenchymal stem cell therapy. Cell Tissue Res. 2019;375(3):563-574.

49. Singh N, Mohanty S, Seth T, Shankar M, Dharmendra $\mathrm{S}$, Bhaskaran S. Autologous stem cell transplantation in refractory Asherman's syndrome: A novel cell based therapy. J Hum Reprod Sci. 2014;7(2):93.
50. Santamaria X, Cabanillas S, Cervelló I, Arbona C, Raga F, Ferro J, et al. Autologous cell therapy with CD133+ bone marrow-derived stem cells for refractory Asherman's syndrome and endometrial atrophy: a pilot cohort study. Hum Reprod. 2016;31(5):1087-1096.

51. Körbling M, Anderlini P. Peripheral blood stem cell versus bone marrow allotransplantation: does the source of hematopoietic stem cells matter? Blood. 2001;98(10):29002908.

52. Li X, Sun H, Lin N, Hou X, Wang J, Zhou B, et al. Regeneration of uterine horns in rats by collagen scaffolds loaded with collagen-binding human basic fibroblast growth factor. Biomaterials. 2011;32(32):8172-8181.

53. Cervelló I, Gil-Sanchis C, Santamaría X, Cabanillas S, Díaz A, Faus A. Human CD133+ bone marrow-derived stem cells promote endometrial proliferation in a murine model of Asherman syndrome. Fertil Steril. 2015;104(6):15521560.e3.

54. Malhotra N, Bahadur A, Kalaivani M, Mittal S. Changes in endometrial receptivity in women with Asherman's syndrome undergoing hysteroscopic adhesiolysis. Arch Gynecol Obstet. 2012;286(2):525-530.

55. Galleu A, Riffo-Vasquez Y, Trento C, Lomas C, Dolcetti $\mathrm{L}$, Cheung TS, et al. Apoptosis in mesenchymal stromal cells induces in vivo recipient-mediated immunomodulation. Sci Transl Med. 2017;9(416):eaam7828.

56. de Witte SFH, Luk F, Sierra Parraga JM, Gargesha M, Merino A, Korevaar SS, et al. Immunomodulation By Therapeutic Mesenchymal Stromal Cells (MSC) Is Triggered Through Phagocytosis of MSC By Monocytic Cells. Stem Cells. 2018;36(4):602-615.

57. Ng YH, Rome S, Jalabert A, Forterre A, Singh H, Hincks CL, Salamonsen LA. Endometrial Exosomes/Microvesicles in the Uterine Microenvironment: A New Paradigm for Embryo-Endometrial Cross Talk at Implantation. Ward WS, ed. PLoS One. 2013;8(3):e58502.

58. 58. Da Silveira J, Andrade GM, Perecin F, Meireles FV, Winger QA, Bouma GJ. Isolation and Analysis of Exosomal MicroRNAs from Ovarian Follicular Fluid. In: Methods in Molecular Biology (Clifton, N.J.). Vol 1733. ; 2018:53-63.

59. Da Silveira JC, de Ávila ACFCM, Garrett HL, Bruemmer JE, Winger QA, Bouma GJ. Cell-secreted vesicles containing microRNAs as regulators of gamete maturation. J Endocrinol. 2018;236(1):R15-R27.

60. Tesfaye D, Gebremedhn S, Salilew-Wondim D, et al. MicroRNAs: tiny molecules with a significant role in mammalian follicular and oocyte development. Reproduction. 2018;155(3):R121-R135.

61. Álvarez V, Sánchez-Margallo FM, Macías-García B, Gómez-Serrano M, Jorge I, Vázquez J, et al. The immunomodulatory activity of extracellular vesicles derived from endometrial mesenchymal stem cells on CD4+ T cells is partially mediated by TGFbeta. J Tissue Eng Regen Med. 2018;12(10):2088-2098. 
62. Blázquez R, Sánchez-Margallo FM, Álvarez V, Matilla E, Hernández N, Marinaro F, et al. Murine embryos exposed to human endometrial MSCs-derived extracellular vesicles exhibit higher VEGF/PDGF AA release, increased blastomere count and hatching rates. Afink GB, ed. PLoS One. 2018;13(4):e0196080.

63. Zadehmodarres S, Salehpour S, Saharkhiz N, Nazari L. Treatment of thin endometrium with autologous platelet-rich plasma: a pilot study. JBRA Assist Reprod. 2017;21(1):54-56.

64. Chang Y, Li J, Wei L-N, Pang J, Chen J, Liang X. Autologous platelet-rich plasma infusion improves clinical pregnancy rate in frozen embryo transfer cycles for women with thin endometrium. Medicine (Baltimore). 2019;98(3):e14062.

65. Middleton KK, Barro V, Muller B, Terada S, Fu FH. Evaluation of the effects of platelet-rich plasma (PRP) therapy involved in the healing of sports-related soft tissue injuries. Iowa Orthop J. 2012;32:150-163.

66. Molotkov AS, Popov EN, Sudakov DS, Aivazyan TA, Alexandrova LA, Dymarskaya YR. Experience of intrauterine application of anti-adhesive gel based on hyaluronic acid in the prevention of Asherman's syndrome in patients with the pathology of the uterine cavity and severe forms of endometriosis. J Obstet and Female Dis. 2017;66(6):12-19. (In Russian).

67. Tkachenko LV. Method of preventing adhesive disease after myomectomy. J Volgogr State Med Univ. 2019;71(3):7073. (In Russian).

68. Tsapanos VS, Stathopoulou LP, Papathanassopoulou VS, Tzingounis VA. The role of Seprafilm bioresorbable membrane in the prevention and therapy of endometrial synechiae. J Biomed Mater Res. 2002;63(1):10-14.

69. Zheng F, Xin X, He F, Liu J, Cui Y, Meta-analysis on the use of hyaluronic acid gel to prevent intrauterine adhesion after intrauterine operations, Exp Ther Med. 2020;19(4):26722678.

70. Hong M-K, Ding D-C. Seprafilm ${ }^{\circledast}$ Application Method in Laparoscopic Surgery. JSLS J Soc Laparoendosc Surg. 2017;21(1):e2016.00097.

71. Fei Z, Bin Z, Xin X, Fei H, Yuechong C. Meta-analysis on the use of hyaluronic acid gel to prevent recurrence of intrauterine adhesion after hysteroscopic adhesiolysis. Taiwan J Obstet Gynecol. 2019;58(6):731-736.

72. Lapworth JW, Hatton P V, Goodchild RL, Rimmer S. Thermally reversible colloidal gels for three-dimensional chondrocyte culture. J R Soc Interface. 2012;9(67):362-375.

73. Yoshioka H, Mikami M, Mori Y, Tsuchida E. A Synthetic Hydrogel with Thermoreversible Gelation. I. Preparation and Rheological Properties. J Macromol Sci Part A. 1994;31(1):113-120.

74. Yoshioka H, Mikami M, Mori Y, Tsuchida E. A Synthetic Hydrogel with Thermoreversible Gelation. Ii. Effect of Added Salts. J Macromol Sci Part A. 1994;31(1):121-125.
75. Yoshioka H, Mori Y, Cushman JA. A synthetic hydrogel with thermoreversible gelation, III: an NMR study of the solgel transition. Polym Adv Technol. 1994;5(2):122-127.

76. Yasuda A, Kojima K, Tinsley KW, Yoshioka H, Mori Y, Vacanti CA. In Vitro Culture of Chondrocytes in a Novel Thermoreversible Gelation Polymer Scaffold Containing Growth Factors. Tissue Eng. 2006;12(5):1237-1245.

77. Lu Y, Wittemann A, Ballauff M, Drechsler M. Preparation of Polystyrene-Poly(N-isopropylacrylamide) (PS-PNIPA) Core-Shell Particles by Photoemulsion Polymerization. Macromol Rapid Commun. 2006;27(14):1137-1141.

78. Li Z, Ngai T. Macroporous Polymer from CoreShell Particle-Stabilized Pickering Emulsions. Langmuir. 2010;26(7):5088-5092.

79. Cheikh Al Ghanami R, Saunders BR, Bosquillon C, Shakesheff KM, Alexander C. Responsive particulate dispersions for reversible building and deconstruction of $3 \mathrm{D}$ cell environments. Soft Matter. 2010;6(20):5037.

80. W. Wang, H. Liang, R. Cheikh Al Ghanami, L. Hamilton, M. Fraylich, K.M. Shakesheff, et al. Biodegradable Thermoresponsive Microparticle Dispersions for Injectable Cell Delivery Prepared Using a Single-Step Process. Adv Mater. 2009;21(18):1809-1813. 


\title{
I Биомиметики для терапии заболеваний эндометрия
}

\author{
Мария В. Коновалова ${ }^{1}$, Дарья С. Царегородцева ${ }^{1,2}$, Римма А. Полтавцева ${ }^{3}$, Елена В. Свирщевская ${ }^{1,3}$ \\ ${ }^{1}$ Институт биоорганической химии им. академиков М. М. Шемякина и Ю. А. Овчинникова РАН, Москва, Россия \\ ${ }^{2}$ Первый Московский государственный медицинский университет им. И. М. Сеченова Минздрава РФ, Москва, Россия \\ ${ }^{3}$ Научный центр акушерства, гинекологии и перинатологии им. акад. В. И. Кулакова Минздрава РФ, Москва, Россия
}

\section{Резюме}

Одной из острых проблем России является вторичное бесплодие женщин детородного возраста. Оно часто вызвано повреждением базального слоя эндометрия при выполнении гинекологических процедур: дилатации полости матки, лечебно-диагностическом выскабливании полости матки, кесаревом сечении, операциях на матке, а также после беременностей, протекающих с осложнениями. Как результат могут развиваться гипо- или гиперметрио3, а также формироваться внутриматочные спайки - синехии, приводящие к развитию синдрома Ашермана. Несмотря на большое количество накопленных клинических данных, отсутствует эффективный способ лечения вторичного бесплодия. В настоящее время с определенным успехом для терапии гипометриоза и синдрома Ашермана используют различные биополимеры и композиты на основе биополимеров с включением активных молекул, генов, их кодирующих, обогащенной тромбоцитами плазмы крови, стволовых клеток или микровезикул/экзосом стволовых клеток. Для использования в клинике сертифицированы гели на основе гиалуроната натрия, карбоксиметилцеллюлозы, полиэтиленоксида, коллагена и другие. Гели биополимеров являются, с одной стороны, разобщающими стенки матки препаратами (барьерная функция), а, с другой стороны, могут работать, как носители биологически активных молекул и клеток.
Биомиметики с разной эффективностью способны стимулировать регенерацию и нормализацию эндометрия, что способствует восстановлению репродуктивной способности. Методики лечения на основе биомиметиков находятся в стадии исследований. В обзоре приведены данные по эффективности лечения патологий эндометрия матки с помощью биотерапевтических подходов.

\section{Ключевые слова}

Бесплодие, гипометриоз, гиперметриоз, синдром Ашермана, барьерные материалы, биогели, биомиметики. 